\title{
LNG Safety Research: FEM3A Model Development
}

\author{
Quarterly Report \\ 01-01-05 - 03-31-05
}

\author{
For: \\ U. S. Department of Energy \\ National Energy Technology Laboratory \\ 626 Cochrans Mill Road \\ Pittsburgh, PA 26507 \\ DOE Project Officer: Gary Sames \\ sames@netl.doe.gov \\ Contract: DE-FG26-04NT42030
}

\author{
Authors: \\ Jerry Havens, University of Arkansas \\ and \\ Iraj A. Salehi \\ Gas Technology Institute \\ 1700 S. Mount Prospect Rd. \\ Des Plaines, IL 60018 \\ Iraj.Salehi@gastechnology.org
}

May 10, 2005 
DISCLAIMER: This report was prepared as an account of work sponsored by an agency of the United States Government. Neither the United States Government nor any agency thereof, nor any of their employees, makes any warranty, express or implied, or assumes any legal liability or responsibility for the accuracy, completeness, or usefulness of any information, apparatus, product, or process disclosed, or represents that its use would not infringe privately owned rights. Reference herein to any specific commercial product, process, or service by trade name, trademark, manufacturer, or otherwise does not necessarily constitute or imply its endorsement, recommendation, or favoring by the United States Government or any agency thereof. The views and opinions of authors expressed herein do not necessarily state or reflect those of the United States Government or any agency thereof. 


\section{LNG Safety Research: FEM3A Model Development Quarterly Report 01-01-05-03-31-05 \\ Contract: DE-FG26-04NT42030}

This quarterly report for DE-FG26-04NT42030 covers a period from January 1, 2005 to March 31, 2005. GTI's activities during the report quarter were limited to administrative work. The work at the University of Arkansas continued in line with the initial scope of work. Quarterly report from University of Arkansas is herewith attached. 


\title{
Vapor Dispersion and Thermal Hazard Modeling
}

\author{
Fourth Quarterly Report \\ (January-March 2005) \\ Prepared by \\ Jerry Havens \\ Tom Spicer \\ Chemical Hazards Research Center \\ University of Arkansas \\ Fayetteville, Arkansas 72701
}

\author{
For \\ GAS TECHNOLOGY INSTITUTE \\ Contract No. 4GTI-DE-FG26-04NT42030 (Prime) \\ K100029184 (Subcontract) \\ GTI Project Manager \\ Iraj Salehi
}

April 30, 2005 


\section{GTI DISCLAIMER}

LEGAL NOTICE. This report was prepared by the University of Arkansas as an account of work sponsored by the Gas Technology Institute (GTI). Neither GTI, members of GTI, nor any person acting on behalf of either:

a. Makes any warranty or representation, express or implied, with respect to the accuracy, completeness, or usefulness of the information contained in this report, or that the use of any apparatus, method, or process disclosed in this report may not infringe privately owned rights; or

b. Assumes any liability with respect to the use of, or for damages resulting from the use of, any information, apparatus, method, or process disclosed in this report. 


\section{CONTENTS}

$\underline{\text { Part }}$

Page

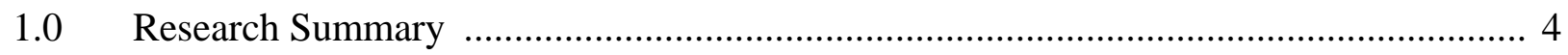

$2.0 \quad$ Program Objective ………………………….................................................. 5

3.0 Program Time Schedule ………………………….............................................. 6

4.0 Work Performed January-March 2005 ......................................................................... 6

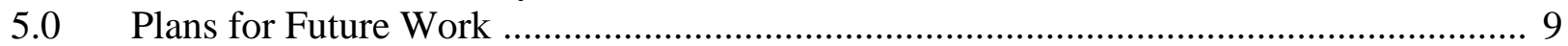

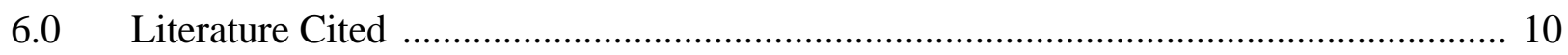


1.0 RESEARCH SUMMARY

Title Vapor Dispersion and Thermal Hazard Modeling

Contractor University of Arkansas

GTI Contract Number: K100029184

Principal Jerry Havens

Investigators Tom Spicer

Contract $\quad$ April $2004-$ March 2006

Period

Objective

To develop the FEM3A model for application to general scenarios involving dispersion problems with obstacles and terrain features of realistic complexity, and for very low wind speed, stable weather conditions as required for LNG vapor dispersion application specified in 49 CFR 193.

Technical The dispersion model DEGADIS specified in 49 CFR 193

Perspective is limited to application for dispersion over smooth, level terrain free of obstacles (such as buildings, tanks, or dikes). There is a need for a dispersion model that allows consideration of the effects of terrain features and obstacles on the dispersion of LNG vapor clouds.

Project

Milestones

A. Simulation of Low-Wind-Speed Stable Atmospheric Conditions.

A. Verification for Dispersion over Rough Surfaces, With And Without Obstacles.

B. Adapting the FEM3A Model for General Application

Results

In Quarter 4

Work continues to underway to address numerical problems during simulation of low-wind-speed, stable, atmospheric conditions with FEM3A. Steps 1 and 2 in the plan outlined in the first Quarterly report are complete and steps 3 and 4 are in progress. During this quarter, we have been investigating the effect upon numerical stability of the heat transfer model used to predict the surface-to-cloud heat transfer, which can be important for LNG vapor dispersion. Previously, no consideration has been given to ground cooling as a result of heat transfer to the colder gas cloud in FEM3A. The present effort is directed to describing the ground surface temperature decrease as a function of time. 


\subsection{PROGRAM OBJECTIVE}

The primary objective of this research is to develop the FEM3A dispersion model for application to general scenarios involving dispersion problems with obstacle and terrain features of realistic complexity, and for very low wind speed, stable weather conditions as required for LNG vapor dispersion application specified in 49 CFR 193. The program involves three principal tasks:

Task A - Simulation of Low-Wind-Speed Stable Atmospheric Conditions

It has been necessary to validate the FEM3A model with data from neutral (stability) wind tunnel boundary layer experiments, since suitable experimental facilities for simulating a stable boundary layer (at the required scale) in a wind tunnel do not exist. However, the regulatory code (49 CFR 193) requires the model prediction to be made for very low wind speed, stable weather conditions. The FEM3A code has not been applied previously for such conditions, and calculations at the University of Arkansas show that FEM3A simulations of stably stratified conditions are subject to numerical stability problems. We are confident that such problems can be eliminated, and research is underway to modify the turbulence closure model and to verify the model changes by conducting experiments in the University of Arkansas Ultra Low Speed wind tunnel. This is a high priority requirement since the normal application of the code for compliance with the regulation, as well as for application to counter-terrorism issues, requires the simulation to be made for such conditions, which most often are worst-case.

Task B - Verification for Dispersion over Rough Surfaces, With and Without Obstacles

Previous experiments in the CHRC wind tunnel to validate the FEM3A model for prediction of the effect of the presence of tank and dike structures utilized a smooth wind tunnel floor. Recent research work in the CHRC wind tunnel indicates that the presence of the smooth floor combined with the low wind speeds required to simulate the dense gas effects involved in LNG vapor dispersion can result in the tendency for the boundary layer near the floor to laminarize. Under such conditions the wind tunnel flow is not similar to the atmospheric wind flow because field conditions are normally fully turbulent (laminarization does not normally occur at field scale). There are strong indications that the experimental data from the wind tunnel would be more applicable to field conditions, and therefore more useful for model validation, when the floor is artificially roughened.

The primary purpose of this task will be to repeat and extend former experiments using uniform roughness elements covering the wind tunnel floor to create turbulence properties similar to field scale wind conditions. The roughness that will be used has already been characterized in a related research program; consequently, only the gas concentration measurements will have to be repeated. The resulting data set(s) will be a valuable addition to the data archives demonstrating the FEM3A model for application to LNG vapor dispersion prediction.

Data from this Task will be used to verify the FEM3A model for applications involving dispersion over rough surfaces (for example, suburban housing) with and without the presence of obstacles such as tank and/or dike structures and industrial buildings. The product of this task 
will be an advanced turbulence closure model (for describing the turbulent mixing involved in the dispersion process) that will allow for more realistic description of dispersion problems with obstacle and terrain features of greater complexity (the real world).

Task C - Adapting the FEM3A Model for More General Application

As more complex applications of the FEM3A model are proposed, it is anticipated that there will be additional questions that can best be addressed by experimentation in the CHRC wind tunnel. The major advantage of this approach is that the specific questions regarding the application of the model to different scenarios can be addressed experimentally without having to recreate all of the experimental conditions in the real scenario, and without the high cost and insufficient controllability that is inherent in larger scale field tests. FEM3A simulations of more complex scenarios will inevitably require experimental verification efforts, and the continued availability of the CHRC wind tunnel for such verification is a necessary adjunct for the successful standardization of the FEM3A model for general application. Examples of complex scenarios that will be considered are evaluation of vapor fences for containment of flammable gases and aerosols, scenarios containing multiple obstacles, and major terrain features.

\subsection{PROGRAM TIME SCHEDULE}

Tasks A and B will be pursued concurrently because they are coupled. However preparations for Task A, which are computational in nature, will be initiated first, with concurrent experimental validation efforts immediately following. Tasks A and B are expected to require six quarters for completion. Task $\mathrm{C}$ will be the primary effort during the last two Quarters, but it will require continuing experimental verification work.

$$
\underline{\mathrm{Q} 1} \quad \underline{\mathrm{Q} 2} \quad \underline{\mathrm{Q} 3} \quad \underline{\mathrm{Q}} \quad \underline{\mathrm{Q} 5} \quad \underline{\mathrm{Q} 6} \quad \underline{\mathrm{Q}} \quad \underline{\mathrm{Q} 8}
$$

Task A

$\begin{array}{lcccccccc}\text { Numerical Stability } & \text { X } & \text { X } & \text { X } & \text { X } & & & & \\ \text { Task B } & & \text { X } & \text { X } & \text { X } & \text { X } & \text { X } & \text { X } & \text { X } \\ \text { Model Verification } & & & & & & & & \text { X } \\ \text { Task C } & & & & & & & \text { X }\end{array}$

\subsection{WORK PERFORMED DURING JANUARY-MARCH (QUARTER 4)}

Primary effort has continued on Task A. Equipment repair and replacement tasks necessary to begin experiments under Task B are complete.

Efforts continue to fix the numerical stability problem for application of FEM3A to low wind speed, stable atmospheric conditions. Our approach uses as a base case the field scale release conditions for which we have carried out the experimental verification of FEM3A thus far. The 
base-case is the tank and high-dike configuration described in previous reports with a continuous, steady, release of 0.6 cubic meters LNG per second into the annular space around the tank. Simulation of worst case regulatory conditions is the requirement: $2 \mathrm{~m} / \mathrm{s}$ wind (at 10 meters elevation), stable atmosphere (Pasquill-Gifford Stability Class F), relative humidity 50\%, and $3 \mathrm{~cm}$ surface roughness. A methodical approach is underway, with introduction of potential problem areas one at a time:

1. Simulation of a base case, with no gas release and with no obstacles, and regulatory conditions - except for D stability (this is a base case to ensure the code's handling of the simulation of the wind field)

2. Same as (1) with LNG release (this will introduce the additional complication of dense gas insertion into the boundary layer)

3. Same as (1) with F stability (this will introduce the additional complication of the F stability condition, but without the complications of alteration of the flow by obstacles)

4. Same as (3) but with LNG release (adding the complication of the insertion of the LNG into the boundary layer)

5. Same as (1) with Dike and Tank (testing the code for handling the simulation of the wind field around obstacles - no problems anticipated)

6. Same as (5) with LNG release

7. Same as (5) but with F stability (testing the code for handling the simulation of the wind field around obstacles, with stable atmospheric conditions)

8. Same as (7) with LNG release

Steps 1 and 2 are complete and steps 3 and 4 are in progress. The simulations in steps 1 and 2 were field scale, obstacle-free simulations made with $2 \mathrm{~m} / \mathrm{s}$ wind (at $10 \mathrm{~m}$ elevation), $3 \mathrm{~cm}$ surface roughness, D stability, for a 10 minute release of $272 \mathrm{~kg} / \mathrm{s}$ LNG $(0.6 \mathrm{m3} / \mathrm{s} \mathrm{LNG})$. As described in Quarterly Report No. 2, these simulations initially indicated a numerical instability that began at the inflow boundary and propagated down the domain. This instability problem was overcome by limiting the upwind (x-direction) aspect ratio to 25; the upwind aspect ratio is the ratio of the maximum alongwind (x-direction) grid spacing to the minimum vertical grid spacing. Guidance in Volume 5 suggested that the maximum aspect ratio should not exceed 50. Simulations showed that the aspect ratio limit of 50 was adequate downwind of the source and in the lateral direction, so the changes (aspect ratio) appear to result from the requirement for simulation at the lower (regulatory worst-case) wind speed. The initially specified grid also showed discontinuities in the concentration profile when a gas release was simulated; this problem was overcome by reducing the minimum vertical grid spacing to $0.3 \mathrm{~m}$. This experience indicates that the minimum vertical grid spacing may need to be further decreased when the F stability simulations are considered.

Previously, no consideration has been given to ground cooling as a result of heat transfer to the colder gas cloud. The present effort is directed to describing the ground surface temperature decrease as a function of time. Kunsch and Fannelop (1995) considered how to model the decreasing surface temperature using an analytical approximation for the temperature distribution in a semi-infinite solid. A similar approach was also reported by Eckert and Drake (1972). Eckert and Drake show that the analytical approach is valid for a step change in cloud 
temperature. The numerically integrated form of the equations suggested by Kunsch and Fannelop agree with the analytical solution of Eckert and Drake. Luikov (1968) provides the analytical solution for the ground-to-cloud heat transfer to a passing cloud of constant temperature (as observed in the Desert Tortoise test described below). We are focusing on two issues:

- $\quad$ FEM3A has treated the ground surface temperature as constant. Nielsen and Ott (1999) analyzed the temperature, concentration, and heat transfer measurements for one particular ammonia release in the Desert Tortoise test series. In the test they analyzed, the ammonia cloud was present over the sensors located $100 \mathrm{~m}$ downwind of the source for approximately $180 \mathrm{~s}$. While the cloud was present, the temperature and concentration at $1 \mathrm{~m}$ elevation were essentially constant. However, the inferred surface heat flux was not constant while the cloud was present as would be predicted by the surface heat transfer model used currently in FEM3A. Even though the cloud was present for only $180 \mathrm{~s}$, the surface heat flux after $180 \mathrm{~s}$ was approximately $60 \%$ of the original value - due to cooling of the ground surface. Since the temperature of an LNG cloud would be much lower than that considered by Nielsen and Ott, the decrease in heat transfer due to ground cooling would be expected to be more significant for an LNG vapor cloud.

- $\quad$ FEM3A assumes a heat transfer model that is based on a forced convection model. Under low wind speed regulatory conditions, ground-to-cloud heat transfer for an LNG cloud may be more appropriately described with a natural convection model.

A simplified model is being considered which can be incorporated in FEM3A without substantial increase in computational resources. The present model under consideration describes the ground surface temperature and the thermal penetration depth as a function of time using an ordinary differential equation at each of the computational nodes on the ground surface. The present model is being compared with simplified problems which can be modeled analytically. This comparison is complete, and the model was implemented in FEM3A for further evaluation. It is anticipated that the heat transfer effects now under consideration will become even more important as consideration is given to the potential for cloud liftoff, which can be a vapor-cloud-impact mitigation factor.

The ground-to-cloud heat flux added to an element on the bottom of the computational domain $\mathrm{q}$ $\left(\mathrm{W} / \mathrm{m}^{2}\right)$ is modeled in FEM3A with a convective heat transfer coefficient $\mathrm{h}\left(\mathrm{W} / \mathrm{m}^{2} \mathrm{~K}\right)$ and a temperature driving force of $\left(T_{g}-T_{1}\right)$ where $T_{g}$ is the ground surface temperature and $T_{1}$ is the lowest node in the computational domain (in the gas phase). In the original formulation of FEM3A, $\mathrm{T}_{\mathrm{g}}$ was assumed to be constant, and based on observations discussed above, such an assumption would tend to overestimate the ground-to-cloud heat transfer.

At any particular time, the ground-to-cloud heat transfer must also be described by the heat transfer from the ground surface into the ground due to conduction. Conduction through the 
ground surface is modeled with a thermal conductivity of the ground (or substrate) and the temperature gradient in the solid. The solution to such a problem has been extensively studied for boundary conditions such as a constant surface heat flux, a constant surface temperature, and a convective boundary condition assuming the fluid above the solid is at a constant temperature. None of these boundary conditions can model the situation under consideration since the fluid temperature above the solid (in this case the gas vapor/air mixture) is not constant. It has been demonstrated that the temperature profile in the solid can be approximated with

$$
\mathrm{T}_{\mathrm{g}}-\mathrm{T}_{\mathrm{go}}=\frac{\mathrm{q} \delta}{3 \mathrm{k}}\left(1-\frac{\mathrm{x}}{\delta}\right)^{3}
$$

where $T_{\text {go }}$ is the initial ground temperature, $\mathrm{k}$ is the thermal conductivity of the ground, $\delta$ is the penetration depth of the temperature change, and $\mathrm{x}$ is the distance from the ground surface into the solid. Note that $\mathrm{T}_{\mathrm{g}}$, $\mathrm{q}$, and $\delta$ are all time varying in Equation (1). Substituting this into the partial differential equation for conduction in the solid, the surface heat flux is described using

$$
\mathrm{q}=-\left.\mathrm{k} \frac{\partial}{\partial \mathrm{x}}\left(\mathrm{T}_{\mathrm{g}}-\mathrm{T}_{\mathrm{go}}\right)\right|_{\mathrm{x}=0}=-\frac{3 \mathrm{k}}{\delta}\left(\mathrm{T}_{\mathrm{g}}-\mathrm{T}_{\mathrm{go}}\right)
$$

Furthermore, substituting the temperature profile of Equation (1) in the integrated form of the heat conduction equation provides the way to describe $\mathrm{T}_{\mathrm{g}}$ and $\delta$

$$
\frac{\mathrm{d}}{\mathrm{dt}}\left(\delta^{2} \mathrm{q}\right)=12 \alpha \mathrm{q}
$$

where $\alpha$ is the ground thermal diffusivity. Equation (3) can be integrated in time using the Euler scheme used in FEM3A for the quantity $\left(\delta^{2} q\right)$. A second differential equation can be obtained by substituting Equation (2) into (3) as follows:

$$
\frac{\mathrm{d}}{\mathrm{dt}}\left(\delta\left(\mathrm{T}_{\mathrm{g}}-\mathrm{T}_{\mathrm{go}}\right)\right)=-\frac{4 \alpha \mathrm{q}}{\mathrm{k}}
$$

When integrating Equations (3) and (4), the surface heat flux q is modified to take into account radiative cooling present for simulating stable atmospheric conditions as follows:

$$
\mathrm{q}=\mathrm{h}\left(\mathrm{T}_{\mathrm{g}}-\mathrm{T}_{1}\right)+\mathrm{q}_{\mathrm{rad}}
$$

where $\mathrm{q}_{\mathrm{rad}}>0$ for stable conditions and is calculated based on atmospheric measurements.

\subsection{PLANS FOR FUTURE WORK}

Contract tasks are expected to be completed on schedule as shown in Section 3.0. 


\subsection{LITERATURE CITED}

Eckert, E.R.G., and R.M. Drake, Jr., “Analysis of Heat and Mass Transfer,” McGraw-Hill, 1972.

Kunsch, J.P., and T.K. Fannelop, "Unsteady heat-transfer effects on the spreading and dilution of dense gas clouds,” Journal of Hazardous Materials, 43, 169-193, 1995.

Luikov, A.V., “Analytical Heat Diffusion Theory,” J.P. Hartnett, ed., Academic Press, 1968.

Nielsen, M., and S. Ott, “Heat transfer in large-scale heavy-gas dispersion,” Journal of Hazardous Materials, A67, 41-58, 1999. 